\title{
Modern Techniques for Power Swing Detection and Classification - A Review
}

\author{
${ }^{* 1}$ Sudarshan Khond, ${ }^{2}$ Vinay Barhate, ${ }^{3}$ S.B.Bodkhe \\ ${ }^{1,2,3}$ Shri Ramdeobaba College of Engineering and Management, Nagpur \\ Email: Khondsr1@rknec.edu, barhatevt@rknec.edu,bodkhesb@rknec.edu
}

Received: 06th October 2019, Accepted: 31st January 2020, Published: 29th February 2020

\begin{abstract}
Power swing is a transient event in the power system that is incepted by various phenomenons such as sudden loss or sudden addition of load, tripping of line due to faults etc. The conventional Distance relays are set to operate for faults may mal-operate during Power swings which lead to transient instability of the system along with low post fault power transfer capability of the system. To avoid this, a fast acting Power swing detection is required that would issue appropriate tripping signals to the breaker so that post fault power transfer capability is optimized. This paper aims to present modern techniques that reliably and efficiently detect power swing and classify the same into fast or slow and stable or unstable class to avoid false tripping of breakers and ensure maximum post fault power transfer.
\end{abstract}

Keywords

Power Swing, Modern Techniques, Power Transfer Capability, Distance Relays, Detection, Classification

\section{Introduction}

High voltage power system line protection is a critical issue in protection systems. Distance relays which operate according to impedance characteristics set and impedance measured at the point of location are popularly used which have reasonably fast response. However due to certain abrupt switching events in the power system result in typical voltage and current waveforms at the point of impedance-measurement of distance relay cause them to give false trip signals. [3]

One of such event is Power swings in power system during which distance relays mal-operate which cause transient instability in the system. [5] Situation can easily escalate and may even cause black-outs. To overcome such problem, in-step-blocking and out-of-step tripping is provided to the distance relays. The tripping arrangement is so made that post fault power transfer is maximized. Following methods have, so far been reported, by researchers for detection of stable and unstable power swings.

\section{Conventional Method}

A power swing is characterized by oscillation voltage and current at the bus. Also, impedance measured by the relay also oscillates and frequency of oscillations of impedance as function of time as shown. Condition corresponds to constant excitation to the machine and constant terminal voltage at the bus. Hence rotor angle of the machine is function of impedance goes on oscillating based on transient [6].

An additional Mho relay is installed to block unstable power swing which covers some area in addition to the area of distance relays step (Fig.1.0) . Rotor angle-delta of synchronous machine that undergoes the transient revolves in circle as a function of impedance. Thus it enters in outer Mho relay first before entering in the step of distance relay. There's a time delay between distance relays step and the additional Mho relay so that it gives sufficient time to inner relay step to operate for faults covered in the relays zone. However if the power swing on machine is too fast, inner step of the distance relay will operate earlier than the blocking step provided by Mho relay thus causing mal-operation of relay. To overcome above problem, auxiliary relays are required that block the tripping signal. Following are some methods that have evolved to overcome problems with conventional scheme in addition to explore more features and more efficient operation.

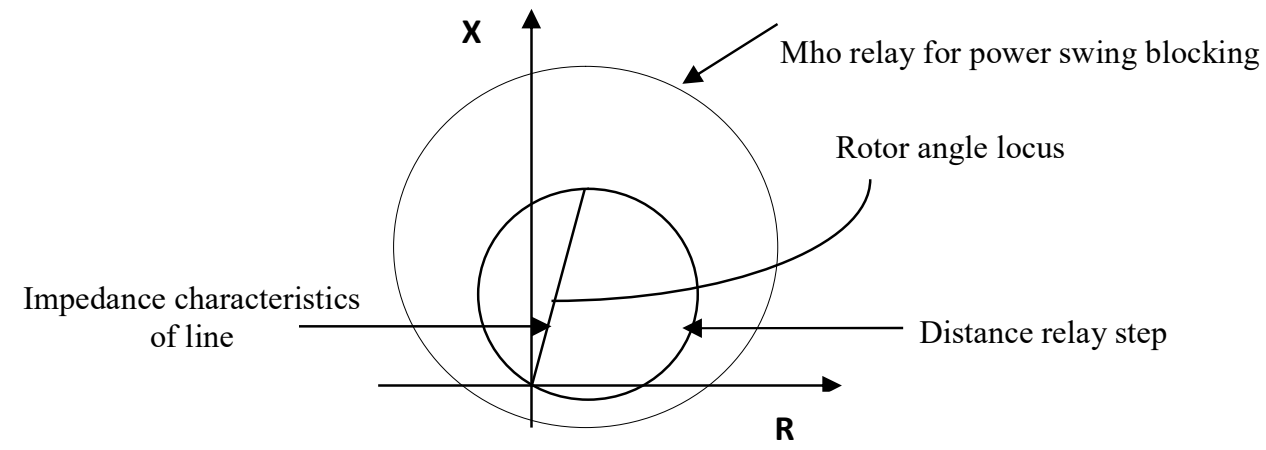

Fig 1: Typical Conventional Mho Relay Scheme for Protection against Power Swing 
Power Swing Detection by Rate of Impedance Variation:

Figure 1.1 show a simple 2-line system used to simulate power swing effect with the specifications as shown. Here sending end is modelled with the machine under consideration and receiving end as the infinite bus. Both the line are $280 \mathrm{Km}$ long and fault is created at the middle of line- 2 at $0.6 \mathrm{sec}$. for 5 cycles of fault current. As stated earlier, oscillating voltage and current waveforms are observed along with oscillating impedance as function of time shown in Figure 1.2, 1.3 and 1.4 respectively.[4]

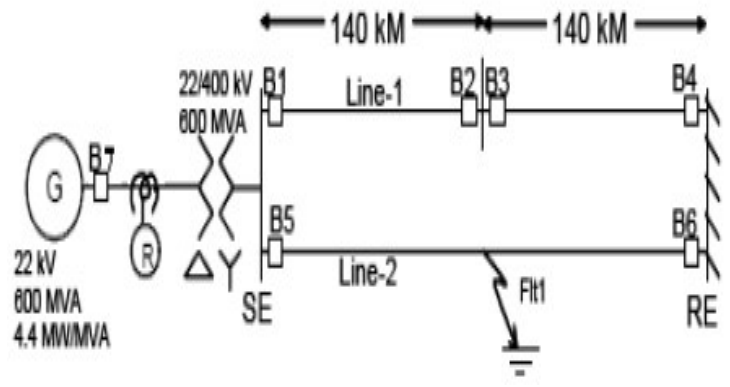

Fig 1.1: Simulink Diagram for Two-area System

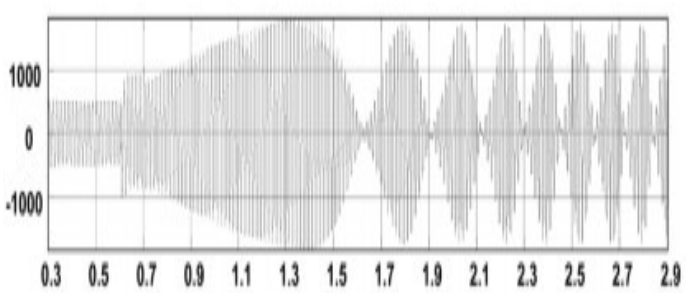

Fig 1.3: Current Waveform

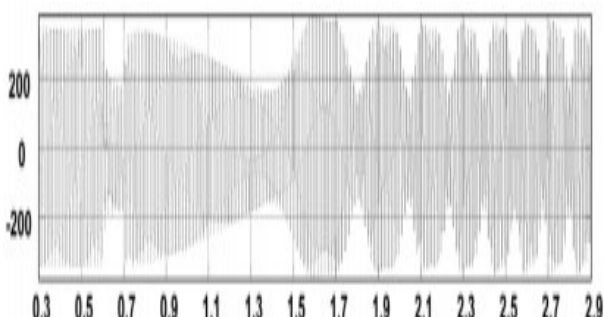

Fig 1.2: Voltage Waveform

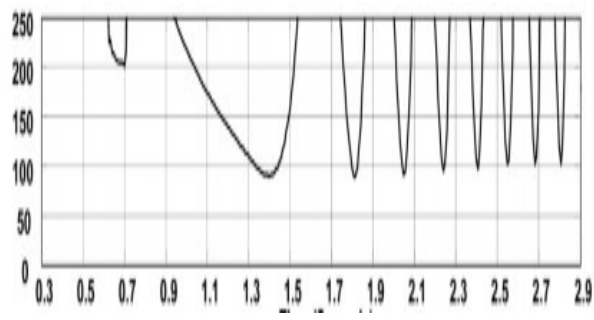

Fig 1.4: Impedance Waveform

Thus by measuring rate at which impedance varies, power swing can be detected [2]. Once the rate goes beyond a certain threshold, blocking signal can be issued by the relay. However such arrangement cannot detect symmetrical faults that occur during power swing. Also, rate of change of impedance takes a while to go below a threshold which makes relay take a longer time to operate and hence causing problem in identifying slow and fast power swings.

Another noteworthy observation for this protection scheme is that for high resistance-ground fault, change in impedance from steady-state to transient and post fault. Thus a high resistance ground fault may not be detected by this technique[1].

\section{Reduced Resistance and its Rate of Change}

During power swings, resistance measured by the relay changes continuously but in case of fault, resistance maintains itself at a steady, low value except for the instant of fault. This phenomenon is used to differentiate between fault and power swing. Fig1.5 shows variation of resistance during power swing.

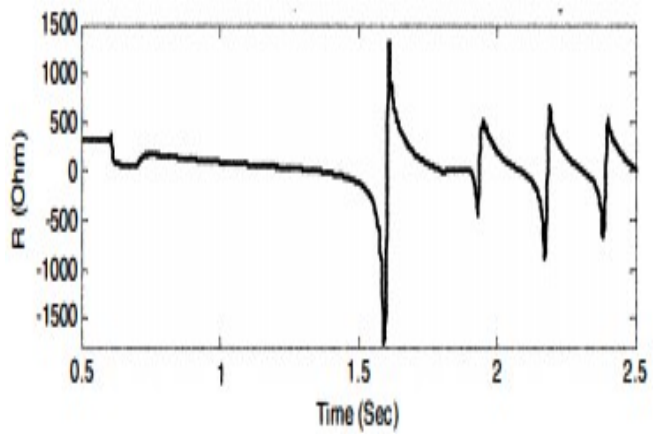

Fig. 1.5: Resistance Measured 
Here, fault is created at $1.35 \mathrm{sec}$. for $0.1 \mathrm{sec}$. It is evident from the fig. that fault resistance remains nearly constant at a low value compared to that in power swing [1]. The locus of resistance remains fairly same for both fast and slow power swing. However fault resistance drops during slow swing by a substantial amount bringing ambiguity in discrimination of three phase faults during power swing as value of resistance is very small in both the cases. Thus this technique also brings in delayed blocking signal from the relay

\section{Rate of Change of Swing-Centre Voltage}

A system that can be modelled to two source equivalent, Swing-Centre voltage is referred to magnitude of voltage at point of measurement being very low and two sources being 180 degree apart. The method monitors rate at which $\mathrm{V}^{*}$ (power factor) which remains constant during a fault and varies during power swing. Swing centre voltage can be approximated as : $\mathrm{SCV}=\mathrm{V}^{*}$ (Power factor)(Fig. 1.6).

During power swings, rate of this swing-centre is found to be changing as:

$$
\mathrm{d}(\mathrm{SCVI}) / \mathrm{dt}=-(\mathrm{El} / 2) \sin (\mathrm{d} / 2)(\mathrm{dd} / \mathrm{dt})
$$

Where El is positive sequence magnitude of sending end voltage Es. Hence, rate of change of swing centre voltage becomes unique parameter for fault and swing condition. As rotor angle moves from 0 to 180 , rate of change of swing centre crosses a threshold.(Fig. 1.7). This becomes unique condition for detection of power swing. [8]

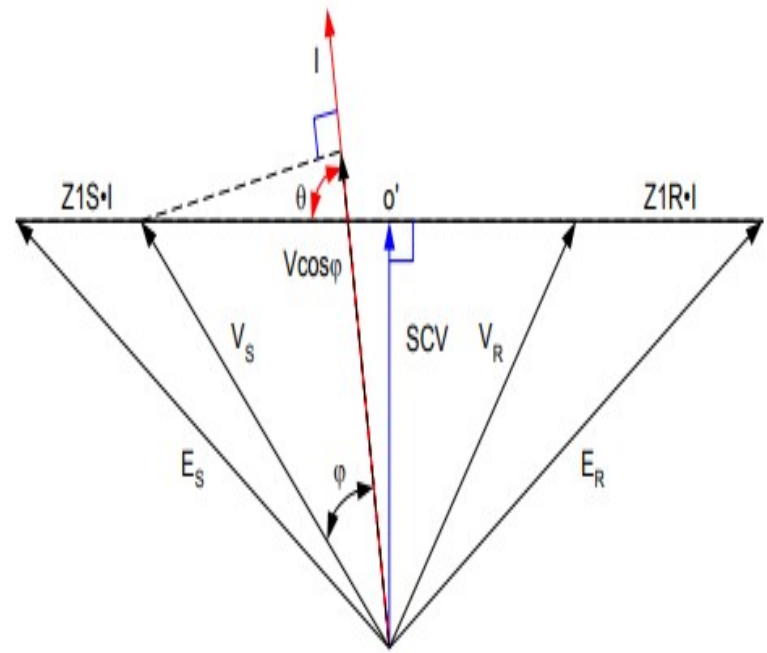

Fig. 1.6: Phasor Representation for SCV1

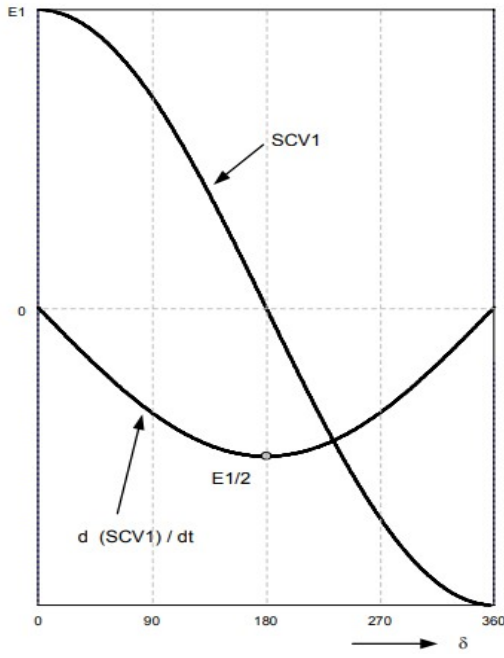

Fig. 1.7: Variation of SCV1 and d(SCV1)

However, this technique also encounters problems such as delayed blocking signal owing to large time for detection. It also faces difficulty in discrimination between high resistance single line to ground fault and power swing as the Swing-Centre for voltage does not remain constant for high impedance single line to ground fault. [1]

\section{Detection of Power Swings with the help of Superimposed Measurements}

Voltage and current waveforms measured during a power swing consists of superimposed waveforms. This phenomenon is utilised to discriminate fault condition from power swing condition. It is claimed that this method can distinguish between fast and slow power swing and can also discriminate between symmetrical and unsymmetrical faults [10].

Method considers current during fault as sum of prefault and fault current. Thus by subtracting prefault component from post-fault component, superimposed value of current can be obtained. There are two methods by which this is done : 1 . Relay compares last data with current sample and give a high pulse soon as it detects the difference. 2. Relay compares the value of stored data from the fault inception and the current sample(Fig. 1.8(a)). Thus power swing can be detected as superimposed components are present for all the time(Fig.1.8(b)). 


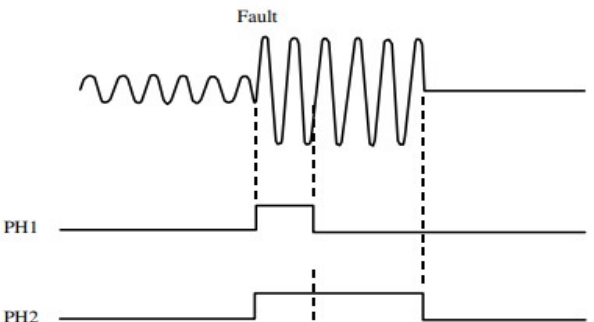

Fig. 1.8 (a): Fault Inception and Current Sample

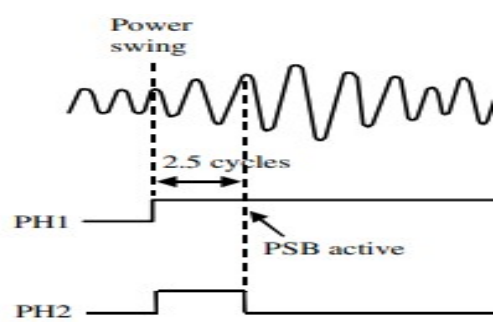

Fig. 1.8 (b): Superimposed Components

Certain faults that occur at power swing centre i.e. when the power angle is close to 180 deg., difference between superimposed component in fault and power swing isn't much thereby making it difficult to classify power swing. [1]

\section{Rate of Change of Energy in Current Signal}

This method uses samples taken from current signal of which fourier transform is taken and energy of the signal is found out. There is significant change in rate of change of energy in current signal during fault. However during power swing, change in sum of energies of the signal remains close to zero. (Fig. 1.9)

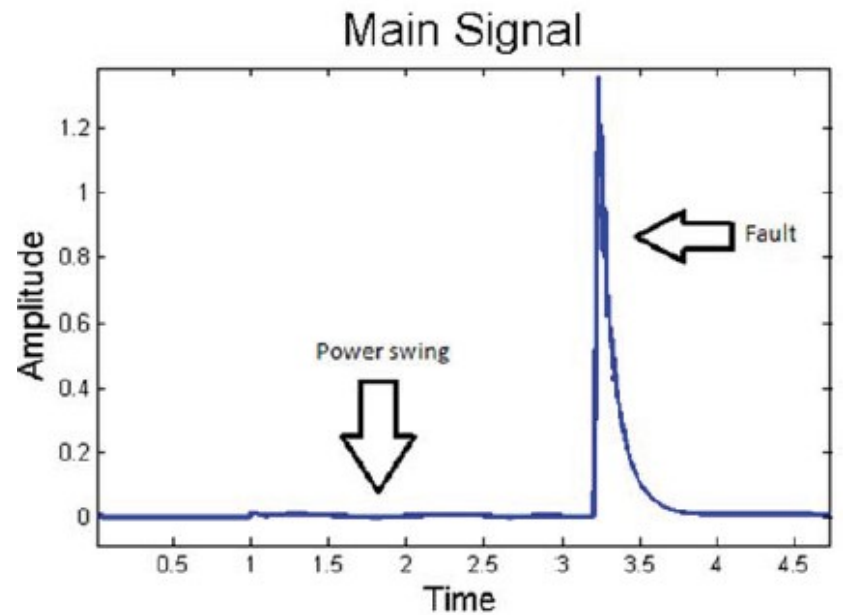

Fig. 1.9: Amplitude of Sum of Energies of the Signal against Time

Samples are taken from the signal under consideration, individually from all three phases. Energy of the sampled data is Calculated as $E_{\mathrm{s}}<=\mathrm{x}(\mathrm{n}), \mathrm{x}(\mathrm{n})>=\sum \bmod (\mathrm{x}(\mathrm{n}))^{2}$

Later, sum of obtained energies can be calculated as $\operatorname{Sum}\left(E_{s}\right)=\sqrt{ }\left(E_{s}(a)+E_{s}(b)+E_{s}(c)\right)$

Afterwards, Fourier transform is applied to energy signal obtained from above and fundamental frequency spectrum is used to discriminate between fault and power swing.

Proposed algorithm is tested on Three phase fault during power swing and high resistance ground fault during power swing and power swing was detected in relatively good speed with the algorithm.[7]

\section{Power Swing Detection with S-Transform and MLPNN}

In this method, multilayer perceptions are used for classification problem. Algorithm successfully discriminates between unstable (Fig2.0) and stable (Fig 2.1) power swing. Signal attributes are extracted with the help of STransform that uses sliding window of frequencies in the signal. Signals used for neural network training is active power. Method detects fault, stable swing and unstable power swing with about $90 \%$ efficiency. This method is tested only on three phase faults and requires to be tested for discrimination between fault during power swing, fast and slow power swing and ground fault with high resistance. [9] 


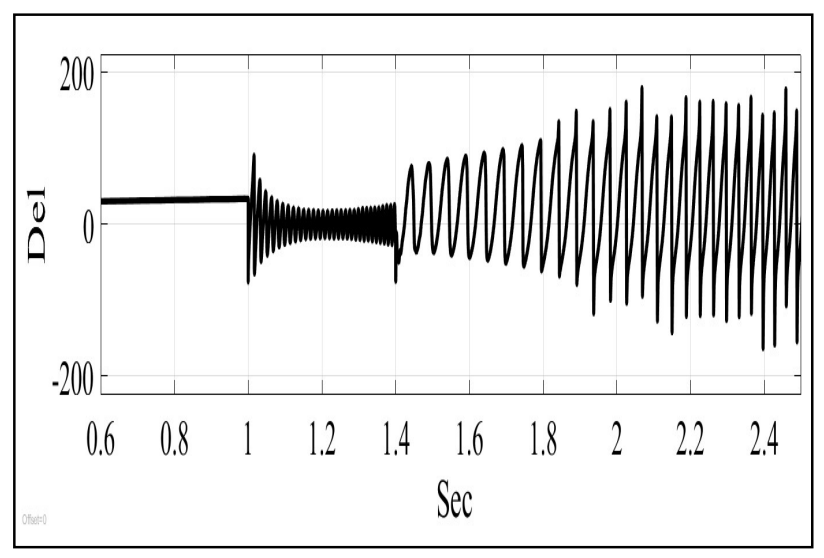

Fig 2.0: Rotor Angle Variation during Unstable Power Swing

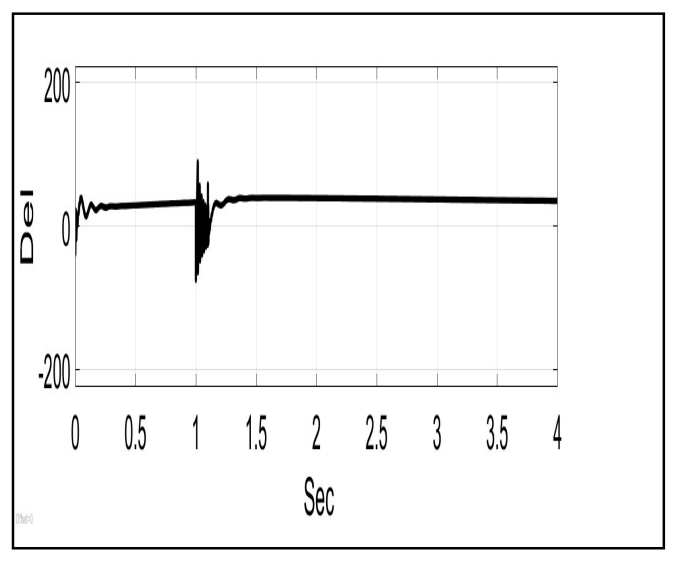

Fig 2.1: Rotor Angle Variation during Stable Power Swing

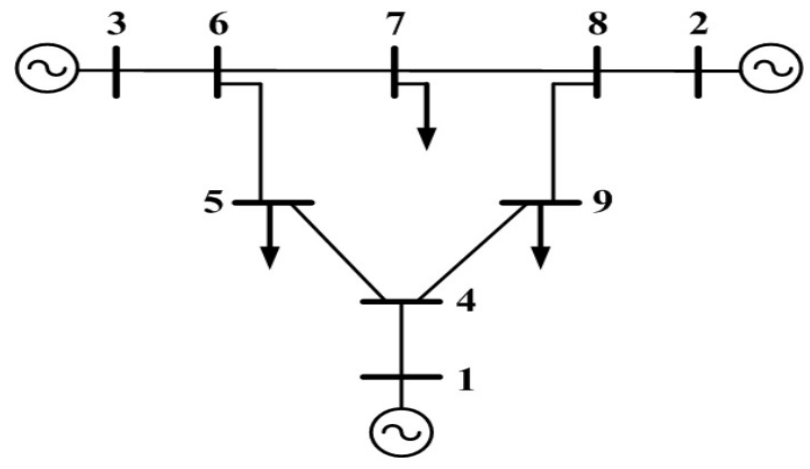

Fig 3.0: IEEE 9 Bus System

\section{Result \& Discussion}

Stable and Unstable swing in Fig 2.1 and Fig 2.0 are obtained in MATLAB Simulink by creating a fault for 0.1 sec and $0.4 \mathrm{sec}$ at $1 \mathrm{sec}$ on load bus 5 (Fig 3.0) respectively and thereby opening the faulty section of the line. Rotor power and excitation for machine under consideration are taken as constant hence due to loss of load, rotor angle starts oscillating during unstable swing.

Thus ANN can be trained for classification of Swing type. However scope lies in testing this method with unsymmetrical fault, high resistance ground fault, slow and fast swings and for faults during power swings.

\section{Conclusion}

A Review of total 7 studies as reported here by various Researchers shows evolution of Power Swing detection techniques that have overcome the anomalies in the classification algorithms. Conversional method can only classify stable and unstable swing for a slow moving swing that does not involve unsymmetrical faults, ground faults with high resistance.

Method based on changing rate of measured impedance again faces difficulty to identify fast and slow swing, unsymmetrical faults and ground faults with high resistance. Changing rate of resistance measured overcomes above difficulties but fails to identify faults in the course of power swing.

Rate of change of Swing impedance gives identification but algorithm takes longer time to block the signal and also fails to detect single line to ground fault with high resistance. Superimposed current detection technique can corrects these problems but faces challenges when fault occurs during swing when angle is close to 180 degree. Rate of change of energy in current signal is unaffected by all the mentioned challenges but is estimated to be costly to implement. ANN based classification method is also free from all the errors in detection but requires a lot of time to train offline data for ANN. Hence for given system, techniques classification should be chosen considering the trade-off between above techniques. 


\section{References}

1.P.K. Nayak, J. Ganeshwara Rao, P.Kundu, A.K. Pradhan and P. Bajpayi, 2010,A Comparitive Assessment of Power Swing Detection Techniques in Joint International Conference on Power Electronics, Drives and Energy Systems \& 2010 Power India, 20-23Dec. 2010

2. Z. Gao and G. Wang,1991, A new power swing block in distance protection based on a microcomputerprinciple and performance analysis in Advances in Power System Control, Operation and Management (APSCOM-91) International Conference on, 1991, pp. 843-847: IET.

3. A. Abdullah and K. Butler-Purry, 2018, Distance protection zone 3 misoperation during system wide cascading events: The problem and a survey of solutions," Electric Power Systems Research, vol. 154, pp. 151$159,2018$.

4. N. Fischer, G. Benmouyal, D. Hou, D. Tziouvaras, J. Byrne-Finley, and B. Smyth, 2012, Do system impedances really affect power swings - Applying power swing protection elements without complex system studies in Protective Relay Engineers, 2012 65th Annual Conference for, 2012, pp. 108-119: IEEE.

5. P. Kundur, N. J. Balu, and M. G. Lauby, Power system stability and control. McGraw-hill New York, 1994.

6. Demetrios A. Tziouvaras and Daqing Hou, SE Laboratories literature, 2003

7.Beharooz Taheri, Sirus Salehimehr, Farazad Razavi, 2019, A New Method for Fast Power Swing Detection Using the Rate of Change of Energy in the Current Signal" in 27th Iranian Conference on Electrical Engineering (ICEE2019), 2019

8. G. Benmouyal, D. Hou, and D. Tziouvaras, 2004, zero-setting power-swing blocking protection, Opresented at the 31 st Annu. Western Protective Relay Conf., Spokane, W A, Oct. 2004

9. Ahmad Farid Abidin, Azah Mohamed, Hussain Shareef, 2011, Power swing detection for correct distance relay operation using S-transform and neural networks in 5th International Power Engineering and Optimization Conference (PEOCO2011), Shah Alam, Selangor, Malaysia,2011

10. Milad Afzali, Ahad Esmaeilian, 2012, A novel algorithm to identify power swing based on superimposed measurements in 11th International Conference on Environment and Electrical Engineering 